\title{
Prevalence of Epidermal Growth Factor Receptor Mutations in Patients with Non-Small Cell Lung Cancer in Turkish Population
}

\author{
Gaye Güler Tezel ${ }^{1}$, Ebru Şener ${ }^{1,2}$, Çisel Aydın ${ }^{1}$, Sevgen Önder ${ }^{1}$ \\ ${ }^{1}$ Department of Pathology, Hacettepe University School of Medicine, Ankara, Turkey \\ ${ }^{2}$ Clinic of Pathology, Erzurum Regional Training and Research Hospital, Erzurum, Turkey
}

\begin{abstract}
Aims: Epidermal growth factor receptor mutation analysis in non-small cell lung cancer is important for selecting patients who will receive treatment with tyrosine kinase inhibitors. In this study, we aimed to investigate the prevalence of epidermal growth factor receptor mutations and mutation patterns in the Turkish population.

Methods: We retrospectively reviewed molecular pathology reports of 959 cases with lung cancer analysed for epidermal growth factor receptor mutations. We analysed all four epidermal growth factor receptor exon mutations using a real-time polymerase chain reaction platform.

Results: In this study, the epidermal growth factor receptor mutation rate in the Turkish population was $16.7 \%$ (160 of 959). The epidermal growth factor receptor mutation frequency was significantly higher
\end{abstract}

in women $(37.1 \%, \mathrm{n}=96)$ than in men $(9.1 \%, \mathrm{n}=64)$ $(p<0.001)$. In addition, the epidermal growth factor receptor mutation rate was higher in the adenocarcinoma histologic type $(\mathrm{p}<0.001)$. Patients with mutations were older than those without mutations $(\mathrm{p}=0.003)$. The most frequent mutations were exon 19 deletions $(48.8 \%$, 78/160) and exon $21 \mathrm{~L} 858 \mathrm{R}$ point mutations (38.1.1\%, $61 / 160)$. We also detected compound mutation patterns in three cases $(1.9 \%)$.

Conclusion: The prevalence of epidermal growth factor receptor mutations in the Turkish population was slightly higher than that in the Caucasian population and lower than that in the East Asian population. The results of this study may provide guidance in personalized therapy of non-small cell lung cancer in the Turkish population.

Keywords: Non-small cell lung cancer, epidermal growth factor receptor mutation, ethnicity
Lung cancer is one of the most common causes of cancer deaths in men and women (1). It is the most common cancer in men and the fifth most common cancer in women in Turkey (2). Most lung cancer patients receive their diagnosis when their cancer is already advanced or metastatic, and the 1-year survival rate is unfortunately less than $15 \%$ if the cancer is not treated (3).
Epidermal growth factor receptor $(E G F R)$ is a receptor tyrosine kinase (TK) of the ErbB family. Mutations in the TK domain of $E G F R$ lead to autophosphorylation and therefore a continuous activation in the TK region. Consequentially, abnormal expression of EGFR results in tumour cell proliferation, angiogenesis, invasion, metastasis and inhibition of apoptosis $(4,5)$.

\footnotetext{
Address for Correspondence: Dr. Gaye Güler Tezel, Department of Pathology, Hacettepe University School of Medicine, Ankara, Turkey Phone: +90 $3123051563 \quad$ e-mail: gayejp@yahoo.com

Received: 8 March $2017 \quad$ Accepted: 17 August 2017 •DOI: 10.4274/balkanmedj.2017.0297

Available at www.balkanmedicaljournal.org

Cite this article as:

Tezel GG, Şener E, Aydın Ç, Önder S. Prevalence of Epidermal Growth Factor Receptor Mutations in Patients with Non-Small Cell Lung Cancer in Turkish Population. Balkan Med J 2017;34:567-71

${ }^{\circ}$ Copyright 2017 by Trakya University Faculty of Medicine / The Balkan Medical Journal published by Galenos Publishing House.
} 
In the TK domain of $E G F R$, activating somatic mutations from exons 18 to 21 were first found in patients with lung adenocarcinoma in 2004 (6). In the 2004 studies, most of the lung cancer patients responding to EGFR TK inhibitors (TKIs), such as erlotinib and gefitinib, reportedly had EGFR mutations $(6,7)$. Some clinical characteristics (Asian origin, never smoked, female gender and histologic adenocarcinoma subtype) are associated with the presence of EGFR mutations in patients with non-small cell lung cancer (NSCLC) (8). However, selection of the patients to be treated should be according to the EGFR mutation analysis results, rather than these clinicopathological characteristics (9).

In earlier studies, the EGFR mutation frequency reportedly varied proportionally among different ethnic groups $(10,11)$. To the best of our knowledge, no study has investigated the prevalence of EGFR mutations and mutation profiles in a large series of the Turkish population. The purpose of this study was to identify EGFR mutation prevalence, mutation types and clinicopathological characteristics of these patients in the Turkish population.

\section{MATERIALS AND METHODS}

\section{Patients and samples}

Ethics committee approval was received for this study from the ethics committee of Erzurum Regional Training and Research Hospital (Date of approval: 21 June 2016; number: 3773205853-4099). In this study, we retrospectively reviewed molecular pathology reports from 963 cases with NSCLC analysed for EGFR mutations at the Department of Pathology, Hacettepe University, from December 2011 through February 2015. However, in four cases, we did not conduct EGFR mutation analysis, because we could not retrieve sufficient and/or good quality DNA. Therefore, 959 patients were included in the study. The median age of the patients was 60 (range 22-87); 250 patients $(26.1 \%)$ who were tested for $E G F R$ mutations were diagnosed in our pathology department and 709 patients (73.9\%) were diagnosed in other pathology laboratories from different regions of Turkey (Samsun, Erzurum, Trabzon, Gaziantep, etc.) and referred to our laboratory for mutation analysis. Specimens diagnosed as adenocarcinoma (698 cases, $72.8 \%$ ), NSCLC not otherwise specified (NSCLC-NOS) (243 cases, $25.3 \%$ ) and squamous cell carcinoma (18 cases, $1.9 \%$ ) were included.

We obtained tumour samples for EGFR analysis from different origins, including primary lung lesions or metastatic lesions. We used formalin-fixed paraffin-embedded (FFPE) tissues, cell blocks and stained cytology slides for EGFR mutation testing.

\section{DNA extraction and quantification}

The pathologist marked the tumour samples on the haematoxylin and eosin-stained sections to choose the tumour-rich areas, and then these areas were manually macrodissected on 8-mmthick unstained sections to eliminate as many non-malignant, stromal and contaminating inflammatory cells as possible. We used single-use sterilized scalpels to prevent contamination. Genomic DNA was isolated from FFPE and cell blocks using a QIAamp DNA FFPE tissue kit (Qiagen, Germany) according to the manufacturer's instructions. For stained (either haematoxylin and eosin, Papanicolaou or Giemsa) cytology slides, DNA was extracted using the phenol-chloroform method (12). Samples that contained at least $25 \%$ tumour cells were tested. The genomic DNA concentration was quantified using spectrophotometry (NanoDrop 2000, Thermo Scientific, Waltham, MA).

\section{Real-time polymerase chain reaction}

We analysed all four EGFR exon mutations (exons 18, 19, 20 and 21) using EntroGen's EGFR mutation analysis kit on an Applied Biosystems StepOnePlus real-time polymerase chain reaction (PCR) platform. Mutational analysis was accomplished for all the samples as described in the kit procedure.

\section{Statistical analysis}

The data were analysed using SPSS version 18 for Windows. We expressed continuous variables as median and categorical data as percentages. We used the chi-square test to compare EGFR mutation status with clinicopathological characteristics. Differences in continuous measurements between two groups (EGFR mutation status and age) were examined by the Student's t-test. We considered a two-tailed $\mathrm{p}<0.05$ to indicate statistical significance.

\section{RESULTS}

Of the 959 samples (700 men, 259 women), 698 were adenocarcinoma, 243 were NSCLC-NOS and 18 were squamous cell carcinoma. The overall mutation rate was $16.7 \%$ (160 of 959). EGFR mutations were significantly more frequent in females $(37.1 \%)(n=96)$ than in males $(9.1 \%)(\mathrm{n}=64)(\mathrm{p}<0.001)$. We found that patients with $E G F R$ mutations were significantly older than those without $E G F R$ mutations $(\mathrm{p}<0.001)$. The distribution of mutation cases according to diagnosis were $142 / 698(20.3 \%)$ adenocarcinoma, 18/243 (7.4\%) NSCLC-NOS and 0/18 (0\%) squamous cell carcinoma. We observed a statistically significantly higher $E G F R$ mutation prevalence in adenocarcinomas $(\mathrm{p}<0.001)$. 
Mutations were detected in 117/677 (17.3\%) primary and 43/282 (15.2\%) metastatic pulmonary tumour samples. We did not see any differences between primary and metastatic samples $(p=0.441)$. In addition, no significant difference was found between FFPE (resections materials and biopsies) tissues and cytologic materials in terms of the rate of EGFR mutation $(\mathrm{p}=0.927)$.

Unfortunately, of 959 patients, we could determine only 35 patients' smoking histories. Although the difference was not statistically significant, EGFR mutations were more frequent in non-smoking patients $(10 / 25)$ than in smokers $(2 / 10)$. Clinical characteristics of 959 patients with NSCLC who were subjected to EGFR mutation analysis and their association with $E G F R$ mutations are summarized in Table 1.

Of 160 mutation cases, the most common mutation was an in-frame deletion in exon 19, comprising $48.8 \%$ (78/160) of all mutations found, followed by a point mutation ( $L 858 R)$ in exon 21 , comprising $36.9 \%$ (59/162) of mutations. These two most common drug-sensitive mutations comprised $85.7 \%$ of all mutation cases. The other rarely seen drugsensitive mutations were exon $18 G 719 \mathrm{X}$, observed in nine cases (5.6\%), and an exon 21 L861Q mutation, seen in two patients (1.2\%). In addition, an exon 20 mutation was found in nine cases (5.6\%); eight were patients with exon 20 insertion mutations, and one case had an exon 20 T790M point mutation. Instead of classical mutation patterns, we detected compound mutation patterns in three cases (1.9\%). In two of these cases, the exon 19 deletion and exon 20 T790M point mutation were detected together, while an exon 21 L858R point mutation and exon 18 G718X point mutation was detected together in one patient. EGFR mutation status patterns are shown in Table 2.

TABLE 1. Characteristics of all patients according to EGFR gene mutation

\begin{tabular}{|c|c|c|c|c|c|}
\hline \multirow{2}{*}{ Characteristics } & & \multirow{2}{*}{$\mathrm{n}(\%)$} & \multicolumn{2}{|c|}{$E G F R$ gene mutation status } & \multirow{2}{*}{$\mathrm{p}$ value } \\
\hline & & & Mutated (\%) & Wild type (\%) & \\
\hline Patients & & $959(100)$ & $160(16.7)$ & $799(83.3)$ & \\
\hline \multirow[t]{2}{*}{ Sex } & Female & $259(27)$ & $96(37.1)$ & $163(62.9)$ & \multirow{2}{*}{$<0.001$} \\
\hline & Male & $700(73)$ & $64(9.1)$ & $636(90.9)$ & \\
\hline \multirow[t]{2}{*}{ Age } & Mean $\pm \mathrm{SD}$ & $050(100)$ & $62.8 \pm 11.1$ & $59.6 \pm 10.0$ & \multirow{2}{*}{$<0.001$} \\
\hline & Median (min-max) & $939(100)$ & $63(31-87)$ & $60(22-86)$ & \\
\hline \multirow[t]{3}{*}{ Histologic type } & Adenocarcinoma & $698(72.8)$ & $142(20.3)$ & $556(79.9)$ & \multirow{3}{*}{$<0.001$} \\
\hline & NSCLC, NOS & $243(25.3)$ & $18(7.4)$ & $225(92.6)$ & \\
\hline & Squamous cell carcinoma & $18(1.9)$ & 0 & $18(100)$ & \\
\hline \multirow[t]{4}{*}{ Sample types } & Primary lung samples & $677(70.6)$ & $117(17.3)$ & $560(82.7)$ & \multirow{2}{*}{0.441} \\
\hline & Metastatic samples & $282(29.4)$ & $43(15.2)$ & $239(84.8)$ & \\
\hline & FFPE tissues (resections, biopsies) & $799(83.3)$ & $140(16.7)$ & $697(83.3)$ & 0927 \\
\hline & Cytologic samples & $160(16.7)$ & $20(16.4)$ & $102(83.6)$ & 0.021 \\
\hline \multirow[t]{3}{*}{ Smoking status } & Current/former smoker & $10(1)$ & $2(20)$ & $8(80)$ & \multirow{3}{*}{0.260} \\
\hline & Never smoker & $25(2.6)$ & $10(40)$ & $15(60)$ & \\
\hline & Missing data & $924(96.4)$ & & & \\
\hline
\end{tabular}

TABLE 2. Type of EGFR gene mutation and their distribution in the study population

\begin{tabular}{|c|c|c|c|}
\hline$E G F R$ mutation status & & No of patients & $(\%)$ \\
\hline Exon 18 & G719X & 9 & 5.6 \\
\hline Exon 19 & Deletion & 78 & 48.8 \\
\hline \multirow[t]{2}{*}{ Exon 20} & Insertion & 7 & 4.4 \\
\hline & T790M & 2 & 1.2 \\
\hline \multirow{2}{*}{ Exon 21} & L858R & 59 & 36.9 \\
\hline & L861Q & 2 & 1.2 \\
\hline $\mathrm{CM}$ & & 3 & 1.9 \\
\hline
\end{tabular}




\section{DISCUSSION}

Determining the presence of $E G F R$ mutations is crucial in terms of selecting patients with advanced or metastatic lung cancer who will receive treatments with TKIs, such as gefitinib or erlotinib, because activating mutations in the EGFR gene in lung tumours is associated with an effective and dramatic response to TKIs (6). In this study, we tried to determine the EGFR mutation frequency of 959 patients with NSCLC and found it to be $16.7 \%$ in the Turkish population. We found a higher EGFR mutation frequency in women, the adenocarcinoma histological subtype and the elderly population.

This is the first comprehensive study investigating the EGFR mutation rate in the Turkish population. Because our study provides an $E G F R$ mutation profile in a wider patient population, and tumour samples used in the EGFR mutation analysis were brought from hospitals in different regions of Turkey, we believe that our results reflect the EGFR mutation rate in the Turkish population more accurately.

In the earlier studies, the $E G F R$ mutation prevalence reportedly varied between ethnic groups. For example, this rate was found to be $10 \%-15 \%$ in Caucasian patients (10), whereas it was reported as $40 \%-60 \%$ in East Asian patients (11). The mutation rate we found in Turkish patients (16.7\%) is slightly higher than that reported in earlier studies on Caucasians. Similar to our results, in a study conducted in 2009, the EGFR mutation rate of Caucasians (Spanish patients) was reported as $16.6 \%$ (13).

The frequency of EGFR mutation depends not only on ethnicity but also on gender, NSCLC histological type and smoking status. In many studies, EGFR mutation rates in women have been reported to be higher than those in men (8). In parallel with these results in the literature, we found the frequency of EGFR mutation to be higher in female than in male patients (37.1\% vs. $9.1 \%)$.

We found the rate of EGFR mutation to be $20.3 \%$ in adenocarcinomas and $7.4 \%$ in NSCLC-NOS. In line with earlier studies, we found the mutation rate in the histological subtype of adenocarcinoma to be higher $(\mathrm{p}<0.001)(8)$. However, we did not find EGFR mutations in any of the 18 cases diagnosed with squamous cell carcinoma. In a few studies, the rate of EGFR mutation reported was very low in squamous cell carcinoma (14). However, consistent with our results, other studies could not detect any EGFR mutations in squamous cell carcinoma (10). The most common mutations found in our study were an inframe deletion $(\mathrm{n}=78,48.8 \%)$ in exon 19 and a point mutation (L858R) in exon 21 ( $\mathrm{n}=61,38.1 \%)$. These two mutations are sensitive to treatment and comprise $89.9 \%$ of all mutation cases; this high rate is consistent with the literature $(6,7)$. Exon 18 G719X, exon $21 \mathrm{~L} 861 Q$, exon 20 mutations and compound mutations that we have detected in three patients are rarely seen mutation types. Although exon 20 mutations are usually associated with resistance to EGFR TKIs, recent studies show that new covalent inhibitors have shown efficacy against relapsing disease during previous treatment with an existing EGFR inhibitor $(15,16)$. Other studies have determined the rate of compound mutation to be $7 \%$ (17). Limited data are available in the literature about the response of these mutations to treatment.

The EGFR mutation rate is reported to be higher in nonsmokers than in smokers $(6,7)$. We identified the smoking status of only 35 of 959 patients. The most important reason of our inability to detect a correlation between the smoking status and the frequency of EGFR mutation is that we could only access the smoking history of very few patients.

Aging causes an accumulation of genetic alterations by reducing stem cell fitness; additionally, the prevalence of oncogenic mutations increases with age (18). We found that patients with $E G F R$ mutations were older than those without mutations. In parallel with our results, there are studies in the literature suggesting that the rate of EGFR mutation is higher in the elderly population (19).

Discordances between primary tumours and corresponding metastatic tumours in terms of EGFR mutation status are extremely rare (9). According to the EGFR mutation results of our study, there was no significant difference between primary and metastatic samples. In this study, we observed no significant difference in the mutation rates of cytological specimens and FFPE tissues (resections and biopsies). This may have been due to the sensitive technique (real-time PCR) that we used as the mutation analysis method. Similar results were obtained in studies that also used sensitive techniques (20).

As a result, we found the EGFR mutation rate in the Turkish population to be $16.7 \%$. In line with earlier studies in the literature, we found a higher mutation rate in the adenocarcinoma histological subtype, comparing to all other subtypes. The results of this study may provide guidance in determining a personalized treatment regimen in NSCLC by giving us genetic information about lung cancer in the Turkish population.

\section{Acknowledgements}

We thank to Arda Günay and Aybüke Kabaoğlu for their technical support.

Financial Disclosure: No financial disclosure was declared by the authors.

Conflict of Interest: No conflict of interest was declared by the authors. 


\section{REFERENCES}

1. Jemal A, Bray F, Center MM, Ferlay J, Ward E, Forman D. Global cancer statistics. CA Cancer J Clin 2011;61:69-90.

2. Republic of Turkey, Ministry of Health. Turkey cancer statistics. http://kanser. gov.tr/Dosya/ca_istatistik/ANA_rapor_2012sooonn.pdf. Accessed 1.08.2016.

3. Stella GM, Luisetti M, Inghilleri S, Cemmi F, Scabini R, Zorzetto M, et al. Targeting EGFR in non-small cell lung cancer: lessons, experiences, strategies. Respir Med 2012;106:173-83.

4. Arteaga CL. Overview of epidermal growth factor receptor biology and its role as a therapeutic target in human neoplasia. Semin Oncol 2002;29:3-9.

5. Jorissen RN, Walker F, Pouliot N, Garrett TP, Ward CW, Burgess AW. Epidermal growth factor receptor: mechanisms of activation and signalling. Exp Cell Res 2003;284:31-53.

6. Paez JG, Janne PA, Lee JC, Tracy S, Greulich H, Gabriel S, et al. EGFR mutations in lung cancer: correlation with clinical response to gefitinib therapy. Science 2004;304:1497-500.

7. Pao W, Miller V, Zakowski M, Doherty J, Politi K, Sarkaria I, et al. EGF receptor gene mutations are common in lung cancers from "never smokers" and are associated with sensitivity of tumors to gefitinib and erlotinib. Proc Natl Acad Sci U S A 2004;101:13306-11.

8. Shigematsu H, Lin L, Takahashi T, Nomura M, Suzuki M, Wistuba II, et al. Clinical and biological features associated with epidermal growth factor receptor gene mutations in lung cancers. J Natl Cancer Inst 2005;97:339-46.

9. Lindeman NI, Cagle PT, Beasley MB, Chitale DA, Dacic S, Giaccone G, et al. Molecular testing guideline for selection of lung cancer patients for EGFR and ALK tyrosine kinase inhibitors: guideline from the College of American Pathologists, International Association for the Study of Lung Cancer, and Association for Molecular Pathology. J Mol Diagn 2013;15:415-53.

10. Marchetti A, Martella C, Felicioni L, Barassi F, Salvatore S, Chella A, et al. EGFR mutations in non-small cell lung cancer: analysis of a large series of cases and development of a rapid and sensitive method for diagnostic screening with potential implications on pharmacologic treatment. J Clin Oncol 2005;23:857-65.
11. Kosaka T, Yatabe Y, Endoh H, Kuwano H, Takahashi T, Mitsudomi T. Mutations of the epidermal growth factor receptor gene in lung cancer: biological and clinical implications. Cancer Res 2004;64:8919-23.

12. Sambrook J, Russell DW. Purification of nucleic acids by extraction with phenol:chloroform. CSH Protoc 2006:2006.

13. Rosell R, Moran T, Queralt C, Porta R, Cardenal F, Camps C, et al Screening for epidermal growth factor receptor mutations in lung cancer. $\mathrm{N}$ Engl J Med 2009;361:958-67.

14. Miyamae Y, Shimizu K, Hirato J, Araki T, Tanaka K, Ogawa H, et al Significance of epidermal growth factor receptor gene mutations in squamous cell lung carcinoma. Oncol Rep 2011;25:921-8.

15. Janne PA, Yang JC, Kim DW, Planchard D, Ohe Y, Ramalingam SS, et al. AZD9291 in EGFR inhibitor-resistant non-small cell lung cancer. N Engl J Med 2015;372:1689-99.

16. Sequist LV, Rolfe L, Allen AR. Rociletinib in EGFR-Mutated Non-small cell Lung Cancer. N Engl J Med 2015;373:578-9.

17. Wu JY, Yu CJ, Chang YC, Yang CH, Shih JY, Yang PC. Effectiveness of tyrosine kinase inhibitors on "uncommon" epidermal growth factor receptor mutations of unknown clinical significance in non-small cell lung cancer. Clin Cancer Res 2011;17:3812-21.

18. Ueno T, Toyooka S, Suda K, Soh J, Yatabe Y, Miyoshi S, et al. Impact of age on epidermal growth factor receptor mutation in lung cancer. Lung Cancer 2012;78:207-11

19. Choi YH, Lee JK, Kang HJ, Lee TS, Kim HR, Kim CH, et al. Association between age at diagnosis and the presence of EGFR mutations in female patients with resected non-small cell lung cancer. J Thorac Oncol 2010;5:1949-52.

20. Min KW, Kim WS, Jang SJ, Choi YD, Chang S, Jung SH, et al. Comparison of EGFR mutation detection between the tissue and cytology using direct sequencing, pyrosequencing and peptide nucleic acid clamping in lung adenocarcinoma: Korean multicentre study. QJM 2016;109:167-73 